\title{
LA IMPORTANCIA DE LA CULTURA EN LAS RELACIONES PENINSULARES (SIGLO XV)
}

\author{
ISABEL BECEIRO PITA \\ Centro de Estudios Históricos \\ (CSIC, Madrid)
}

\begin{abstract}
SUMARIO
1. Las aptitudes de los cortesanos.- 2. La formación de los letrados laicos y eclesiásticos.- 3. Actividades diplomáticas y realizaciones culturales.- 4. El reconocimiento de las cualidades propias del embajador.
\end{abstract}

En las últimas décadas se ha puesto de relieve que el factor decisivo para el nombramiento de los agentes diplomáticos en este período no es la vinculación al soberano ni al bando en el poder. Indudablemente, la pertenencia a la sociedad política, en sentido amplio, constituye una condición indispensable. Pero no es suficiente. Es más, se exigen unos requisitos a los tres componentes usuales de las embajadas solemnes, formadas por un noble, un clérigo y un letrado'. Aún cuando son parcialmente diferentes para cada uno de ellos, los aludidos requisitos se pueden

\footnotetext{
'A.H. de Oliveira MARQues, As relações diplomaticas, en "Actas das II Jornadas LusoEspanholas de História Medieval", vol. I, Porto, 1990, pp. 39-59. Para los integrantes portugueses en tiempos del Africano y el ceremonial que el rey estableció para los extranjeros que acudieran a su corte, según el grupo al que pertenecían, véase Virgínia RaU, Relações diplomaticas de Portugal durante o reinado de D. Afonso V, en "Estudos de História Medieval", Lisboa, 1985, pp. 66-81.

"Anuario de Estudios Medievales", 29 (1999)
} 
sintetizar en la experiencia anterior, la adscripción a los organismos de gobierno y el poseer ciertos saberes especializados².

Estos saberes o conocimientos suelen fundamentarse en los estudios jurídicos en grado de bachiller o doctor que tenían, por lo general, los embajadores procedentes de la Iglesia o de los organismos administrativos. Pero tal afirmación puede llevar a pensar que la cultura no era valorada por sí misma, sino que se concebía como una capacitación técnica. De ella estarían, además, exentos los caballeros, de los que se esperaba, en algunos casos, un asesoramiento de carácter militar.

El objetivo de estas páginas es intentar mostrar que la cultura, además de esta vertiente concreta, tenía una función primordial en la imagen de los diplomáticos bajomedievales. Se deriva del doble papel que desempeñaban éstos, en cuanto encarnación de la autoridad de su soberano y representantes del país y de su corte, que era inherente a su cometido, por encima de las misiones encomendadas. Para ello he analizado diversos datos procedentes de fuentes cronísticas, diplomáticas y literarias sobre la trayectoria de los personajes dedicados a estos menesteres en los tres principales reinos peninsulares - Castilla, Aragón y Portugal-a lo largo del siglo XV y, especialmente durante sus primeros 55 años.

\section{LAS APTITUDES DE LOS CORTESANOS}

Los escasos testimonios conservados dejan traslucir que, al menos varios de los calificados documentalmente como nobles, sobresalían en los círculos de la cultura y destrezas caballerescas.

Realmente, los miembros de la alta nobleza que participan en tareas diplomáticas no son muy numerosos. Lo habitual es que únicamente tengan

\footnotetext{
${ }^{2}$ Armando L. de CARvalho Homem, Diplomacia e burocracia nos finais da Idade Média. A propósito de Lourenço Anes Fogaça, chanceler-mor (1374-1399) e negociador do Tratado de Windsor, en "Estudos e ensaios em homenagem a Vitorino Magalhães Godinho", Lisboa, 1988, pp. 217-228; Isabel BECEIRO PITA, Las negociaciones entre Castilla y Portugal en 1399, "Revista da Faculdade de Letras. História", II série, vol. XIII (Porto, 1986), pp. 149-185; La tendencia a la especialización de funciones en los agentes diplomáticos entre Portugal y Aragón (1412-1465, en "XV Congreso de Historia de la Corona de Aragón". Actas, II: "Relaciones de la Corona de Aragón con los Estados cristianos peninsulares (siglos XIII-XV)", Zaragoza, 1997, pp. 441-457; y La consolidación del personal diplomático entre Castilla y Portugal (1392-1455), en "La Península Ibérica en la Era de los descubrimientos" ("Actas de las III Jornadas HispanoPortuguesas de Historia Medieval"), Sevilla, 1997, II, pp. 1735-1745.
} 
una actuación destacada cuando se trata de acordar una paz, mantener una tregua o mediar en un conflicto bélico, ya sea latente o abierto. Es cierto que la proporción de los calificados como caballeros es relativamente elevada, pero, en su mayoría, tienen como dedicación preferente los oficios de justicia, de la secretaría, o, en menor grado, los hacendísticos, dentro de la administración regia, por lo que pueden encuadrarse en el grupo de los letrados.

Tampoco se encuentran entre ellos autores importantes de la literatura religiosa, doctrinal o poética. Hay que tener en cuenta que, como es lógico, la dedicación intelectual resultaba secundaria para las relaciones exteriores, frente al conocimiento previo del asunto a tratar, del país y de su corte y, muchas veces, la experiencia en embajadas anteriores. Y no hay duda de que cuando estos factores se reunieron en algunos hombres de letras se recurrió a ellos. Durante la segunda mitad de la centuria anterior, tenemos la mejor prueba en las actividades diplomáticas de Pero López de Ayala en Castilla y, en la Corona de Aragón, de Ramón de Perellós, antecesor del homónimo embajador a Castilla en $1430^{3}$.

En el siglo XV se valora en los medios caballerescos la instrucción y el refinamiento. Estas cualidades son consideradas como la consecuencia del desarrollo educativo lógico en un noble que posee buen "seso" o discernimiento, característica que ya se aplica desde el siglo XII castellano al monarca y a algunos de sus familiares y que en la Baja Edad Media se amplía a ciertos aristócratas, sobre todo a los que participan en los órganos de gobierno. Suele concretarse en una conversación agradable y en la capacidad de sintetizar y sacar conclusiones de los acontecimientos expuestos ante ellos. Así son retratados, entre otros magnates, el justicia mayor del reino, Diego López de Estúniga, el almirante de Castilla, Alfonso Enriques,

\footnotetext{
${ }^{3}$ Son bien conocidas las gestiones en Francia, Inglaterra y Portugal de Pero López de Ayala, a quien se debe el Rimado de Palacio, la Crónica de Pedro I de Castilla y las de los primeros Trastamaras. Las embajadas de Ramón de Perellós, vizconde de Roda y Perellós y autor del Viatge al Purgatori de Sant Patrici se efectuaron, sobre todo, con Francia, Nápoles y la corte papal de Aviñón. $\mathrm{M}^{\mathrm{a}}$ Teresa Ferrer I Mallol, Activitats polítiques y militars de Ramon de Perellós (autor del "Viatge al Purgatori de Sant Patrici", durant el regnat de Joan I), en "Medievo Hispano. Estudios in memoriam del Prof. Derek W. Lomax", Madrid, 1995, pp. 159-175 y El consell reial durant el regnat de Martí l'Humà, "XV Congreso de Historia de la Corona de Aragón. Actas, t. I, vol. 2: "El poder real en la Corona de Aragón (siglos XIVXVI)", Zaragoza, 1996, p. 186. La actividad del segundo Ramón de Perellós en las treguas con Castilla en 1430 está documentada en el Archivo de la Corona de Aragón (ACA). Cancillería real. Secretorum, $n^{\circ} 2692, f^{\prime \prime \prime} 43$ v. -46 y 58 v. -59.
} 
que acudieron a Aragón en 1411 y $1412^{4}$, el condestable Ruy López Dávalos, que trató la paz con Portugal en 1399 y $1402^{5}$, don Juan de Silva, conde de Cifuentes, que negoció con Aragón en $1434^{6}$ y el portugués João Gomes de Silva, que lo hizo con Castilla en $1411^{7}$.

Con respecto a algunos personajes especialmente relevantes en la política exterior e interior, se puede advertir el refuerzo de sus rasgos positivos con el énfasis en el saber, que se presenta como un grado superior al discernimiento. No es de extrañar que se ponga especialmente de manifiesto en las referencias a Juan Fernández de Híjar, uno de los máximos colaboradores de Alfonso el Magnánimo y embajador ante el concilio de Constanza, ante la corte lusitana en 1430 y ante Juan II de Castilla en 1437, 1439,1442 y $1447^{8}$, pues según afirma Zurita, que dice seguir en ésto a Lorenzo Valla, une a su condición de descendiente del gran soberano glorioso de la Corona de Aragón una sabiduría y una elocuencia igual o superior a la de sus contemporáneos que habían seguido estudios universitarios:

Hizose elección de la persona de don Juan de Ijar para esta embajada, [la del concilio] principalmente como uno de los principales caballeros de su tiempo, no solo por ser uno de los más grandes barones del reino y de la casa real pero por el valor extremado de su persona, que en la figura y forma y estatura grande y robusta del cuerpo representaba aquella majestad

${ }^{4}$ Crónica de Juan II de Castilla, en Crónicas de los reyes de Castilla, "BAAEE", II, Madrid, 1953, pp. 336 y 342.

Fernán Pérez de Guzmán expone en la semblanza de Diego López de Estúñiga que "segund dizen los que le platicaron, era onbre de buen seso e que en pocas palabras fazia grandes conclusiones" y en la del almirante que fué hombre "de rason breve e corta, pero discreta e atentada, asaz gracioso en su dizir". Generaciones y semblanzas, ed. de J. Domínguez BORDONA, Madrid, 1979, p. 35 y p. 41.

${ }^{5}$ Según Fernán Pérez de Guzmán, fué "muy alegre e graçioso, de dulçe e amigable conuersaçion, muy esforçado e de grande trabaio en las guerras, asaz cuerdo e discreto, la rason breue e corta pero buena e atentada..." Generaciones y semblanzas, o. c., p. 31. Sobre su intervención en los asuntos bélicos y diplomáticos con el país lusitano, véase I. BECEIRO PITA, Las negociaciones entre Castilla y Portugal, pp. 171-173.

${ }^{6} \mathrm{Hernando}$ del Pulgar dice de él que "fablaua muy bien e cosas muy substanciales e conformes ala razon". Los claros varones Despaña, ed. facsímil de la de Sevilla, 1500, Madrid, 1971, fo XXII v., p. 52.

${ }^{7}$ Silva era "conhecido ao mesmo tempo por ser homem forte e ardido e pelo a propósito e saboroso dos seus ditos", según Oliveira Martins, Os filhos de D. João I, reimpresión, Lisboa, 1993, p. 36. 654-655.

${ }^{8}$ ACA. Secretorum, no 2692, f's 111-112. Crónica de Juan segundo, "BAAEE", pp.. 607 


\begin{abstract}
del rey don Jaime el conquistador de quien el descendía por línea de varones. Con esta compostura verdaderamente real, se conformó la excelencia y alteza de ánimo, y con el discurso de grandes negocios fue tenido por un muy sabio y prudente varón y de gran consejo y singular elocuencia, y tan enseñado en las ciencias y letras humanas que afirma dél Lorenzo Vala que se igualó con los más excelentes de toda España y que no había conocido ninguno de los que profesaban aquellos estudios que tuviese mas facundia que él; y así fue comúnmente conocido y estimado como aquel que a sus muy excelentes virtudes y partes juntó el don de grande sabiduría?.
\end{abstract}

Desde luego, este pasaje responde a una semblanza encomiástica y a una voluntad de glorificar a la monarquía, incluso en sus ramas de origen bastardo, a lo que se añade una reivindicación de la elocuencia, ya vigente en el pensamiento romano y en la Plena Edad Media e incrementada en el protohumanismo y el Renacimiento. Sin embargo, esta imagen laudatoria no debió de estar completamente alejada de la realidad, pues la personalidad de don Juan de Híjar impresionó a algunos escritores castellanos que debieron de conocerle directamente. Aún cuando el aristócrata aragonés no esté relacionado con el cancionero que lleva su nombre,la fama de su elocuencia queda de manifiesto en el calificativo que Gómez Manrique le dedicó de "orador muy singular", al lamentar su muerte junto con la de Juan de Mena ${ }^{10}$

Los conocimientos eruditos del resto de los aristócratas implicados en tareas diplomáticas no gozaron de una fama tan amplia. Sin embargo, existen referencias directas o indirectas a la instrucción de algunos de estos nobles, más concretamente a la de Diego López de Estúñiga, Alonso Tenorio y Alfonso Velasco. Del primero se sabe que fue criado durante sus primeros años en el lugar navarro de Castañares por "vn clérigo onrrado e entendido", lo que alude, sin duda alguna, a que adquirió por este medio los rudimentos

\footnotetext{
'Jerónimo ZURITA, Anales de la Corona de Aragón, ed. de Ángel CANELlas LóPEZ, t. 5, Zaragoza, 1974, pp. 408-409. La fuente directa de esta semblanza no es, como podría pensarse, la Historiarum Ferdinandi regis Aragoniae. Quizás esté inspirada en algún fragmento de otra obra de Lorenzo Valla.

10"E por mas me lastimar leuome [la muerte] syn lo tardar aquel de grand perficion Don Iohan d'Ixar d'Aragon, orador muy syngular". GóMEZ MANRIQUE "Recuerda las muertes de Juan de Mena y de Don Jhoan d'Ixar", dentro de Planto de las virtudes e poesía por el marqués de Santillana, en Cancionero, reimpresión en Palencia, 1991 de la ed. de A. PAZ Y MELIÁ, Madrid, 1886, t. II, p. 47.
} 
culturales básicos ${ }^{11}$. Con respecto al segundo, uno de los negociadores con Aragón y Navarra en $1429^{12}$, hay que suponer su gusto por los libros, pues a su muerte, en 1430 , dejó una biblioteca de 24 volúmenes, la primera importante de las pertenecientes a la nobleza castellana, que debió de pasar total o parcialmente a su hijo, el también embajador, y ya citado, Juan de Silva ${ }^{13}$.

El refinamiento de las cortes del siglo XV ha dejado sus huellas en la producción literaria cortesana, con un triple carácter lírico, doctrinal y político, en la que participaron algunos agentes de las relaciones exteriores. Este gusto por la poesía tiene unos claros antecedentes a finales del siglo XIII, durante el reinado de Sancho IV de Castilla: entre 1290 y 1293 Esteban Pérez Florián, caballero portugués exiliado a Castilla, hermano de don Sancho, obispo de Oporto, merino mayor de León en 1283 y 12871289 , y refinado trovador, interviene en diversas negociaciones con Portugal, Francia y Aragón ${ }^{14}$. No se trata de una figura aislada: durante la primera mitad de la centuria siguiente, en la Corona de Aragón, el infante Pedro, hijo de Jaime II fue reputado como hombre de letras, latinista, mecenas y poeta y, en el plano internacional, alcanzó prestigio gracias a las misiones que le encomendaron su hermano Alfonso el Benigno y después su sobrino Pedro el Ceremonioso, aunque éstas se centraron, sobre todo, en el continente ${ }^{15}$.

Como es sabido, las cortes de Juan II y de Alfonso el Magnánimo proporcionaron un clima propicio al desarrollo de la lírica cancioneril. Entre los autores castellanos alcanzaron relativa importancia Juan de Silva y Pedro de Mendoza. Del primero se han conservado cuatro canciones amorosas,

\footnotetext{
"Lope García DE Salazar, Las bienandanzas e fortunas, ed. de A. Rodríguez Herrero, t. IV, Bilbao, 1955, 42).

${ }^{12}$ Crónica de Juan II de Castilla, p. 453. El título que le otorga la crónica es la de notario del reino de Toledo, aunque también era entonces adelantado de Cazorla. Con él va el doctor Fernán González de Ávila, del consejo regio, y dos procuradores de las ciudades.

${ }^{13}$ Isabel BeCEIRO PITA; Alfonso Franco Silva, Cultura nobiliar y bibliotecas. Cinco ejemplos, de las postrimerías del siglo XIV a mediados del siglo XVI, "Historia, Instituciones, Documentos", 12 (1985), pp. 282-291 y 321-324.

${ }^{14}$ Cristina JUlar PÉREZ-Alfaro, Los adelantados y merinos mayores de León (siglos XIII$X V)$, León, 1990, pp. 205-209.

${ }^{15}$ Salvador Claramunt RodrígueZ, El poder real y la cultura en "XV Congreso de Historia de la Corona de Aragón. Actas: El poder real..", t. I vol. 1", Zaragoza, 1996, pp 366-367.
} 
recogidas en el Cancionero de Palacio ${ }^{16}$. En cuanto a Mendoza, fue jefe de una rama menor de los Mendoza, guarda mayor del rey, señor de la villa soriana de Almazán y embajador a Aragón en $1424^{17}$. No es de extrañar que solicite algunas poesías a su pariente Iñigo López de Mendoza, marqués de Santillana, pues intercambia preguntas y respuestas poéticas con Gómez Manrique a propósito del malestar político del reino castellano y coplas elogiosas con Juan de Mena ${ }^{18}$. También el almirante Alfonso Enríquez pudo destacar en este campo, pero, en el estado actual de nuestros conocimientos, no es posible saber si las poesías que se le atribuyen fueron escritas, en realidad, por su nieto homónimo y tercer almirante o por algún miembro de una rama menor. Los embajadores portugueses no han dejado huella poética hasta el final de la centuria, pero probablemente es debido a la carencia de compendios lusos hasta entonces, pues el Cancioneiro Geral de García de Resende, datado en 1516, permite atestiguar la inserción en la cultura cortesana de Ruy de Sande y Ruy de Sousa, negociadores del tratado de Tordesillas y sus preliminares ${ }^{19}$

En conjunto, los datos biográficos sobre estos personajes permiten concluir que la cultura y la instrucción no resultaban excepcionales en ellos, sino que participaban de unas inquietudes comunes a muchos otros nobles que intervenían, en mayor o menor medida, en las decisiones de gobierno. Sin embargo, el hecho de que la mayoría de estos testimonios procedan de fuentes diferentes a las que dan cuenta de su actividad diplomática llevan a pensar que, al menos en la primera mitad del siglo XV, el saber se consideraba un valor sobreañadido para el desempeño de estos menesteres, salvo para los eclesiásticos y letrados. Esta concepción cambia en torno a la década de 1460, ligada a un nuevo impulso en la afirmación del poder de la monarquía.

\footnotetext{
${ }^{16}$ Cancionero de Palacio, ed. de Ana Ma Álvarez Pellitero, Salamanca, 1993. XXXV, p. 31, CXC, p. 187, CCCV, p. 312 y CCCXXVII, pp. 335-336.

${ }^{17}$ Alvar García DE SanTa María, Crónica de Juan II, "Colección de Documentos Inéditos para la Historia de España" ("CODOIN"), t. 99, reimpresión, Vaduz, 1966, p. 333.

${ }^{18}$ Gómez Manrique, Cancionero, t. I, pp. 131-134 y Juan de Mena, Obras completas, ed. de Miguel Ángel Pérez PrIEGo, Barcelona, 1989, 35, p. 77.

${ }^{19}$ Garcia de RESENDE, Cancioneiro geral, Coimbra, 1973, t. II, no 597, p. 117 y n"s 570 , 596 y 608 , pp. 61,109 y 137.
} 


\section{LA FORMACIÓN DE LOS LETRADOS LAICOS Y ECLESIÁSTICOS}

El sector mayoritario de los embajadores está constituido por los que, en sentido amplio, se pueden calificar como letrados: escribanos, secretarios, notarios, juristas y clérigos con estudios universitarios en derecho. En efecto, aún cuando el término letrado se aplique estrictamente a los hombres de leyes puede extenderse perfectamente a los oficios de pluma, dado que para ejercerlos se requiere una capacitación en lectura, escritura, buena caligrafía, nociones de gramática, unos ciertos rudimentos jurídicos relacionados con las fórmulas cancillerescas y los elementos básicos del derecho de su país, tanto el general -o del territorio, en los distintos reinos de la Corona de Aragón- como el local ${ }^{20}$. Además, los secretarios regios dominaban el latín, por ser la lengua de los escritos concernientes a las relaciones con el continente europeo y en Aragón incluso de algunos documentos internos, a juzgar por los datos conocidos sobre el caballero Francisco de Ariño, secretario del Magnánimo y embajador a Castilla en $1426^{21}$.

En efecto, para el período que se extiende hasta 1455 , el de mayor actividad diplomática y para el que se conservan datos más expresivos, se pueden calcular en 132 el conjunto de miembros de las embajadas en los tres países que tratan asuntos que pueden competir a la monarquía como tal y no de carácter fundamentalmente privado ${ }^{22}$. El cómputo se ha realizado

\footnotetext{
${ }^{20} \mathrm{M}^{\mathrm{a}}$ del Pilar RÁBADE OBRADÓ, Las escribanías como conflicto entre poder regio y poder concejil en la Castilla del siglo XV: el caso de Cuenca, "Anuario de Estudios Medievales", 21 (1991), p. 258 y José Bono, Historia del derecho notarial español, t. XXX Madrid, 1982, pp. 207-220.

${ }^{21}$ J. RUIz CALONGE, Valor literario de los preámbulos de la cancillería real catalanoaragonesa en el siglo XV, "Boletín de la Real Academia de Buenas Letras de Barcelona", XXVI (Barcelona, 1954-1956), pp. 205-235 y ACA, Secretorum, reg. n² 2691, f"s 2 r-12.

${ }^{22} \mathrm{La}$ relación de nombres se ha obtenido fundamentalmente a partir de Monumenta henricina, vols. II-XIV, Coimbra, 1960-1973; vizconde de SANTAREM, Quadro elementar das relações politicas y diplomáticas de Portugal com as diversas potencias do mundo, t. I, Paris, 1842, pp. 275-357 y t. III, Paris, 1843, pp. 74-106; Fernão LOPES, Crónica del rei D. João I Lisboa, 1983, vols. I y II; Ruy de PINA, Chronica do senhor rey D. Duarte y Chronica do senhor rey D. Affonso V, Crónicas de Rui de Pina, Porto, 1977, pp. 487-771; J. ZURITA, Anales de la Corona de Aragón, ed. de A. CANEllas LóPEZ, t. V, Zaragoza, 1974; Alvar García de SANTA María, Crónica de don Juan II de Castilla (1420-1434), "CODOIN", ts. XCIC y C, reimpresión, Vaduz, 1966; Crónica de don Juan II de Castilla, Diego ENRíQuez DEL CASTILLO, Crónica del rey don Enrique el cuarto de este nombre, en Crónicas de los reyes de Castilla, ts. II y III, "BAAEE", Madrid, 1953; L. de BARRIENTOS, Refundición de la crónica
} 
excluyendo a los mensajeros y procuradores, salvo cuando éstos últimos reciben plenos poderes para establecer cualquier tipo de alianzas en nombre de su monarca. No obstante, hay que reconocer que, en ocasiones, es muy difícil deslindar las funciones de embajadores y mensajeros, por lo que se ha recurrido a las distinciones de las crónicas como criterio clasificatorio. A estos problemas que conlleva el estimar quiénes componían el personal de las embajadas, se añade otro proveniente de las fuentes cronísticas, e incluso, de los registros regios: a menudo se menciona un único embajador, sin sus acompañantes, y se omite el escribano o secretario, aún cuando, a juzgar por las instrucciones dadas en 1430 por Alfonso el Magnánimo al secretario Pero Pérez $^{23}$, la actividad de éstos podía llegar a tener tanta importancia como la de los enviados solemnes. En consecuencia, es probable que esta cifra fuera, en realidad, más elevada.

Pues bien, de estas 133 menciones de personajes, 81 corresponden a letrados en sentido amplio, es decir, un $61 \%$ del total. Sin duda, la proporción sería mucho mayor: sólo se han incluido aquellos individuos para los cuales hay indicios claros de sus estudios o de su actividad administrativa, aunque cabría introducir también todas las dignidades eclesiásticas, dada la tendencia a valorar la formación universitaria para el acceso al deanato o a las sedes episcopales. Ciertamente, y al igual que ocurre en otros órdenes de la vida, estos ideales no siempre se llevaron a la práctica: algunos dignatarios de la Iglesia no alcanzaron el nivel cultural deseado, a juzgar por la semblanza que Fernán Pérez de Guzmán dedica al cardenal Pedro de Frías, miembro de la embajada castellana a Portugal en $1402^{24}$. También es posible que algunas opiniones no muy favorables sobre determinados personajes estuvieran influidas por la comparación implícita con las individualidades contemporáneas y sobresalientes en su mismo ministerio o por resentimientos personales o familiares.

Por otra parte, no ha sido posible contabilizar adecuadamente el indeterminado acompañamiento de letrados castellanos a Portugal en 1440

del halconero, ed. de J. de M. CARriazo, Madrid, 1946; Antonio de la TORRE y Luis SUÁrez FERNÁNDEZ, Documentos referentes a las relaciones con Portugal durante el reinado de los Reyes Católicos, t. I, Valladolid, 1958.

${ }^{23} \mathrm{Se}$ enmarcan en la embajada a Portugal de Juan Fernández de Híjar. ACA, Cancillería real. Secretorum, reg. $n^{\circ} 2692$, $\mathrm{f}^{\prime \prime \prime} 133$ v. $-135 \mathrm{v}$.

24"Fue onbre de mediana altura, de buen gesto; non muy buen letrado; muy astuto e cabteloso, tanto que por maliçioso era auido. Non fue muy deuoto nin onesto, nin tan linpio de su presona como a su dignidad se convenia". Generaciones y semblanzas, o. c., p. 111. 
- que se han estimado en dos- ni dar cabida a varias menciones de representantes de ciudades aragonesas y castellanas en diversas misiones.

Por lo que concierne al reparto entre los tres reinos, se encuentra en relación directa con la conflictividad bélica del momento o del pasado inmediato y, por tanto, con la necesidad de arbitrajes, conciertos y treguas. Cuando no se tratan este tipo de asuntos o las alianzas matrimoniales los contactos tienen un carácter menos solemne y son llevados a cabo por un único enviado, al tenor de los datos proporcionados tanto por las crónicas como por las cartas e instrucciones dirigidas por los monarcas. En consecuencia, no es de extrañar que resulte mucho más elevado el número de embajadores castellanos a Portugal y Aragón y el de aragoneses a Castilla que el de los que se ocupan de las relaciones entre Aragón y Portugal y que casi no se encuentre entre estos últimos a integrantes de la aristocracia guerrera.

La proporción de los letrados es abrumadora. Oscila de un $83 \%$ a un $48 \%$, situándose el término medio en torno a un $60 \%$, como se ve en el siguiente cuadro:

Asistencias diplomáticas entre los tres principales reinos peninsulares $(1400-1455)$

\begin{tabular}{||l|l|l|l|l||}
\hline \multicolumn{1}{|c|}{ País de origen } & País de destino & Cantidad total & Letrados & Porcentaje \\
\hline Castilla & Portugal & 30 & 18 & $60 \%$ \\
\hline Portugal & Castilla & 32 & 21 & $65,6 \%$ \\
\hline Castilla & Aragón & 32 & 21 & $65,6 \%$ \\
\hline Aragón & Castilla & 26 & 12 & $46 \%$ \\
\hline Aragón & Portugal & 7 & 4 & $57,1 \%$ \\
\hline Portugal & Aragón & 6 & 5 & $83 \%$ \\
\hline
\end{tabular}

Su importancia queda aún más de manifiesto si se tiene en cuenta que no pueden equipararse las menciones de componentes de las embajadas con el número de personajes. En efecto, se advierte

una tendencia gradual a la reiteración de nombramientos en los mismos individuos. Esto lleva a reducir la cifra total a 97, con una proporción de 
letrados que no varía sustancialmente $(52,6 \%)$, ni siquiera en el reparto por reinos.

Miembros efectivos de las embajadas (1400-1455)

\begin{tabular}{||l|l|l|l||}
\hline País & Cantidad & Letrados & Porcentajes \\
\hline Castilla & 48 & 29 & $60,5 \%$ \\
\hline Portugal & 24 & 12 & $50 \%$ \\
\hline Aragón & 25 & 10 & $40 \%$ \\
\hline
\end{tabular}

Entre los aristócratas no faltan personajes elegidos repetidamente para estas tareas. Aparte de las numerosas intervenciones de Juan Fernández de Híjar, hay que mencionar las dos del aragonés Jaime de Luna y de los castellanos Alonso Enríquez, Alonso Tenorio, Juan de Silva y Pedro de Mendoza. Sin embargo, la relación de estudiosos enviados en varias ocasiones es mucho más amplia. En Portugal, se puede constatar para los temas castellanos al prelado Jõao Affonso de Azambuja en 1402 y 1407 y a Martin do Sem en 1411, 1418-1419 y 1423; en Aragón, trata con Castilla el arzobispo de Tarragona Dalmao de Mur en 1423 y 1424 y en Castilla, Juan Alfonso de Zamora es empleado para las relaciones lusitanas de 1421 a 1423 y Fernán López de Burgos en 1432 y 1453. Es más, este último grupo cuenta entre sus filas a los únicos que, con la salvedad del ya citado Híjar, entienden en los asuntos de los dos reinos, con dedicación preferente a uno de ellos. En este sentido, las actuaciones más destacadas corren a cargo de los castellanos Alfonso de Santa María o de Cartagena, Diego González de Toledo y Fernán López de Burgos y de los portugueses Ruy Fernandes, Nuño Martines de Silveira, Jõao Fernandes de Silveira y Ruy Galvão. Por tanto, se puede decir que en los letrados recae habitualmente la responsabilidad de las embajadas.

Solo se ha podido ofrecer aquí un conjunto de datos homogéneo para estos tres reinos y los primeros 55 años de la centuria. No obstante, conviene señalar que un análisis más amplio cronológica y espacialmente, incluyendo la segunda mitad del siglo XIV y las relaciones con Navarra, pondría aún más de relieve la progresiva concentración de las funciones diplomáticas peninsulares en un número reducido de letrados. Resulta lógico, 
pues, aparte de otros motivos, se basa en la conciencia de que los puntos de fricción subsistían durante etapas relativamente largas y que, por tanto, debían nombrarse negociadores que los conocieran total o parcialmente. En concreto, y hasta la década de 1450 , la política ibérica está dominada por las secuelas de Aljubarrota, la intervención en Castilla de los infantes de Aragón, el apoyo más o menos forzado que les presta Alfonso el Magnánimo $\mathrm{y}$, en menor grado, las sucesivas fases de concordia y tensión entre los Avís y los descendientes de Fernando de Antequera. Por tanto, hasta 1407 se encuentran en las relaciones luso-castellanas, esencialmente, los mismos personajes del decenio anterior y en 1429 los embajadores castellanos acuden conjuntamente a Aragón y Navarra. Uno de ellos, el oidor Fernán González de Ávila ya había visitado la corte navarra en 1419, con ocasión del matrimonio entre doña Blanca de Navarra y el infante don Juan de Aragón $^{25}$. A partir de los años centrales del siglo se abre una serie de proyectos matrimoniales, con éxito o fallidos, que, por el lado lusitano, fueron protagonizados por el caballero-doctor Jõao Affonso de Silveira ${ }^{26}$.

Dentro de este sector de letrados, el componente básico está formado por los juristas. A pesar de la parquedad y concisión de las fuentes, se han podido atestiguar 38 doctores, un licenciado y un bachiller, aún cuando sólo se menciona la especialidad de 28 . Entre ellos sobresalen los que tenían el grado de doctor en leyes o lo obtuvieron poco después de su embajada, que llegan a 17. El resto está compuesto por 11 titulados en derecho canónico, algunos también en derecho civil, como Alfonso de Santa María o Cartagena. Aún cuando la documentación califica a 7 como estudiosos de decretos y a 4 de cánones, en la Baja Edad Media estos dos términos eran equiparables. Hay que tener en cuenta que el corpus iuri canonici desarrollaba los conceptos de paz y tregua y, además, era necesario su conocimiento para formalizar las alianzas matrimoniales y examinar los posibles impedimentos por consanguineidad, de cara a evitar una futura anulación papal sobre los enlaces de príncipes e infantes. En conjunto, se consideraba en esta época

\footnotetext{
${ }^{25}$ Álvar GaRcía de SANTA MaRía, Crónica de don Juan II, "CODOIN", t. 100 reimpresión, Vaduz, 1966, p. 49 y J. ZuRITA, Anales de la Corona de Aragón, t. III, Zaragoza, 1669 , p. 136

${ }^{26}$ Para los acontecimientos de la política peninsular anteriores al reinado de los Reyes Católicos, véase L. SUÁREZ FERnÁNDEZ, Relaciones entre Portugal y Castilla en la época del infante don Enrique, 1393-1460, Madrid, 1960 y Luis ADÃO DE FONSECA, Alguns aspectos das relaçôes diplomaticas entre Portugal e Castela em meados do século XV (1449-1456), "Revista da Faculdade de Letras. História", vol. III, Porto, 1972, pp. 51-112.
} 
que los textos del derecho canónico proporcionaban la suma de las pautas de actuación de los gobernantes, completada con argumentos extraídos del pensamiento greco-romano, fundamentalmente del aristotélico ${ }^{27}$.

Los secretarios o los escribanos no son muy cuantiosos. Solo se han podido atestiguar ocho, aunque, como se apuntaba con anterioridad, es probable que integraran todas las embajadas,si bien, en la mayoría de los casos, no se les concedía suficiente relevancia pública como para ser registrados en los textos. Pero entre los enviados por Alfonso el Magnánimo y don João I se encuentran tres de los personajes más notables de las relaciones diplomáticas peninsulares en la primera mitad del siglo XV: Francisco de Ariño, en el primer caso $^{28}$, y Nuno Martins de Silveira ${ }^{29}$ y Ruy Galvão, en el segundo. Los dos lusitanos están vinculados al infante don Duarte, en esa etapa final del reinado de don Jõao en la que el heredero está, de hecho, asociado al trono ${ }^{30}$. Al menos para alguno de estos "oficiales de pluma" se puede constatar también la titulación en derecho civil ${ }^{31}$.

La importancia de los secretarios reside en otro factor: en ocasiones, el desempeño de estos menesteres en una primera embajada parece funcionar como una especie de capacitación práctica que hace posible su aparición

\footnotetext{
${ }^{27}$ Así lo expresa Alfonso García de Santa María en una proposición enviada, de parte de Juan II de Castilla, al rey de romanos, el 20 de noviembre de 1438 . Introduce además varias referencias a San Isidoro, San Ambrosio, San Jerónimo, Cicerón, Valerio Máximo, Platón y, sobre todo, a las Éticas y a la Política de Aristóteles. Archivo General de Simancas (AGS). Estado-K. Leg. 1171, f's 532-537 v.

${ }^{28} \mathrm{El} 14$ de febrero de 1426 Alfonso el Magnánimo da una carta de procuración a su secretario Francisco de Ariño para establecer en su nombre toda clase de ligas y confederaciones con Juan II de Castilla, Juan de Navarra, y con cualquier súbdito de estos reinos, sean de los respectivos consejos o no. Dos días después, el infante don Enrique de Aragón le otorga un poder similar. ACA. Cancillería real, reg. $n^{\circ} 2691, \mathrm{f}^{\prime \prime \prime} 2$ v y r. y 11 v.-12.

${ }^{29} \mathrm{La}$ documentación emanada de la Corona de Aragón pone de manifiesto que, a instancias del mediador Silveira, propuso el Magnánimo, el 1 de abril de 1430, una tregua con Castilla de medio año, a partir del 1 de junio. ACA. Cancillería real. Registro 2680, fo 59 v. Su gestión se extendió a conseguir de los reyes de Navarra y Aragón la ampliación de la tregua. ACA. Cancillería real. Secretorum, reg. $n^{0} 2692$, f"s 62 v. -66

${ }^{30}$ Silveira, ricohombre, era, desde los 18 años, escribano de la puridad de don Duarte Humberto BAQUERO MORENO, A batalla de Alfarrobeira. Antecedentes e significado histórico, Lourenço Marques, 1973, p. 962. Galvão, también noble, fue, sucesivamente, secretario de don Jõao I, don Duarte, el regente don Pedro y Affonso V el Africano, pero se puede considerar que su carrera se inició a los 11 años, cuando entró como criado de don Duarte, en la cámara de éste. Monumenta henricina, t. VI, Coimbra, 1964, $\mathrm{n}^{\circ}$ 61, pp. 205-206.

${ }^{31}$ De Lopo Affonso, enviado a Castilla por el regente don Pedro en 1440 , se sabe que el 1 de noviembre de 1411 era licenciado en derecho civil y residente en Padua. Chartularium universitatis portugalensis, vol. II, Lisboa, 1968, $\mathrm{n}^{\circ} 631$, pp. 38-39. Quizás hubiera obtenido el doctorado cuando realizó su embajada.
} 
posterior como negociador solemne, a juzgar por las actuaciones de Ruy Galvão en el reino castellano, como secretario en 1431 y como embajador en 1453. Es un procedimiento de "aprendizaje profesional" que ya fue utilizado en las relaciones luso-castellanas de finales de la centuria anterior y que abarca igualmente a acompañantes, correos, mensajeros, procuradores, "terceros", mediadores, jueces árbitros y testigos o confirmantes de los acuerdos $^{32}$.

Es probable que el único cargo hacendístico empleado para estas tareas, Pero Gonçalves Malafaia - "vedor da fazenda" de don Duarte, que acude a Castilla en 1431 y 1432 -, fuera también escribano y hubiera que incluirlo en este sector, a juzgar por la trayectoria de Alvar Gonçalves de Maia, quien ejerció de escribano en las delegaciones de 1411 y 1418$1419^{33}$.

Realmente, los maestros de teología no tuvieron un gran papel en la diplomacia peninsular. Su presencia se advierte, más bien, en las relaciones con el continente europeo, la corte papal o las grandes asambleas conciliares. Aquí sólo se ha podido documentar a cuatro: los castellanos Diego de Badán o Mayorga, Luis Álvarez de Paz, Alfonso de Madrigal, el Tostado, y Fernando de Córdoba y en representaciones secundarias, o bien, en el caso de Luis Álvarez de Paz, muy solemnes y compartidas con varios nobles y oficiales. De todas formas, su formación cultural solía rebasar el ámbito de su especialidad. Tras la autorización papal a las enseñanzas teológicas en Salamanca y Valladolid -otorgada en 1381 y 1418 , respectivamente- se tendió a dotar las cátedras con anteriores maestros de lógica y de la filosofía natural, basada en las tesis aristotélicas ${ }^{34}$. Además, no era raro que estos estudiosos unieran a su doctorado el de alguna rama del derecho. La doble titulación de Luis Álvarez de Paz en teología y leyes muestra que los conocimientos de El Tostado, quien destacaba en artes, teología y derecho canónico, eran sobresalientes, pero no excepcionales ${ }^{35}$.

\footnotetext{
${ }^{32}$ I. BeCEIRo PITA, Las negociaciones entre Castilla y Portugal, pp. 151-152.

${ }^{33}$ Sobre éste último, véase Armando L. de CARVALHo Homem, O desembargo regio (13201433), Porto, 1990, p. 281.

${ }^{34}$ Adeline RUCQuOI, Contribution des "studia generalia" à la pensée hispanique médiévale, en "Pensamiento medieval hispano. Homenaje a Horacio-Santiago Otero", coord. de José $\mathrm{M}^{\mathrm{a}}$ SOTO RÁBANOS, I, Madrid, 1998, pp. 760-761.

${ }^{35}$ "Seyendo gran maestro en artes e theología se dispuso a aprender derecho canonico y ceuil: e fue en aquellas facultades bien instruto". Hernando del PULGAR, Los claros varones Despaña, o. c., f' 41 v., p. 90
} 
Si entre los aristócratas se apreciaba, aparte del valor guerrero, su buen entendimiento, su inserción en la cultura cortesana y su elocuencia, la valoración positiva de los clérigos y oficiales de la Corona suele sintetizarse en los adjetivos de docto, sabio o erudito, aplicados bien al conjunto del saber o, en menor grado, a la ciencia jurídica.

Los mayores elogios están destinados a miembros del episcopado. Con una fórmula retórica, que exalta las cualidades de un personaje a través de una aparente negativa a tratar de ellas, Lorenzo Valla enaltece la ciencia y el prestigio de Domingo Ram, titular de la sede oscense en el momento de su embajada a Castilla, fundamentando su opinión en la fama pública, los hechos del prelado y los honores recibidos por él. En cuanto al arzobispo de Tarragona, Dalmao de Mur, lo sitúa en el orden de los escolásticos ${ }^{36}$. Con respecto a los castellanos, las semblanzas que Hernando del Pulgar realiza de Alfonso García de Santa María y Alfonso de Madrigal incorporan, igualmente, la unánime reputación favorable que les otorgaron sus contemporáneos y la formación universitaria, pero valoran también sus escritos y traducciones, y, en el caso del obispo de Burgos, la conversación sobre temas eruditos ${ }^{37}$.

Fuera de las dignidades eclesiásticas, algunos juristas son objeto de alabanza. Pero existe una diferencia con respecto a los anteriores: los elogios resultan más concisos y no versan sobre su dominio del conjunto de los saberes sino sobre su competencia en el oficio. Habitualmente se reducen al epíteto de grandes letrados.

\footnotetext{
${ }^{36}$ "Ex Aragoniae quidem delecti sunt, Dominicus Ramus episcopus Oscensis, quem postea Ilerdensem, ad extremum archiepiscopum Terragonensem... de cuius scientia, vita, autoritate, dicere parum attinet, cum iudicia hominum, hoc est honores habiti, testimonium dicant..." "Dalmaus quo Murus citato agmine scholasticorum..." Lorenzo VALLA, Historiarum Ferdinandi regis Aragoniae, ed. de Pedro LóPEZ Elum, Valencia, 1970, pp. 99 y 124.

${ }^{37}$ Del primero se afirma que "fue criado enla yglesia y en scuela de sciencia e fue gran letrado en derecho canonico e ceuil. Era asi mismo gran filosofo natural... Entre los letrados que fueron escogidos para embiar a vn grand concilio que se fizo en Basilea, Este obispo seyendo dean de Santiago fue vno delos nombrados a quien el rey don Juan mando yr en aquella embaxada, enla qual conocida su sciencia e la esperiencia de sus letras e claras costumbres gano tan gran fama que estando en Roma el papa Eugenio lo proueyo del obispado de Burgos... Torno de lengua latina en nuestra lengua vulgar ciertas obras de Seneca que el rey don Juan le mando reduzir. Era onbre muy estudioso e deleytaua se en platicar las cosas de ciencia". Parte de la semblanza del segundo ya ha sido citada con anterioridad. Básicamente se completa en que "E tan grande era la fama de su saber en todas sciencias que estando en aquel estudio duro grand tiempo que venian ale ver omes doctos. tan bien delos reynos estraños como delos reynos despaña..." Hernando del Pulgar, Los claros varones Despaña, o. c., pp. 84-85 y 91
} 
La excepción más clara concierne a Berenguer de Bardaxí, justicia de Aragón a partir de 1420 y casado con una hermana del obispo Domingo Ram. Quizás por el decisivo papel que tuvo en el Compromiso de Caspe, que decidió conferir la Corona de Aragón a Fernando I, las referencias a su valía son más extensas y expresivas, resaltando, de manera similar a la de los prelados anteriores, la fama de su superioridad frente a los de su mismo cuerpo. Valla sostiene que ninguno de los contemporáneos del jurista ni del autor recuerdan que hubiera en los territorios hispánicos un jurisconsulto de mayor autoridad y, precisamente a propósito de esa reunión de compromisarios, la Crónica de don Juan II de Castilla explica que "era hombre muy letrado a quien todos los Letrados del Reyno daban gran fé" 38 .

Al igual que ocurría con los embajadores de la aristocracia, esta imagen se corresponde con la realidad, al menos con la de las personalidades más sobresalientes. Éstas desarrollan una actividad práctica que, para los letrados en derecho integrados en las instituciones de gobierno, se inserta en la labor legislativa de los monarcas respectivos, y en los prelados se orienta fundamentalmente al interés por la cultura, al engrandecimiento material y artístico de su iglesia catedral y al apoyo a los principales establecimientos educativos de la diócesis.

Es muy difícil trazar los hitos biográficos de estos juristas, ya que no han dejado mucha huella en la documentación ni han recibido, apenas, tratamiento bibliográfico. Por otra parte, el carácter de prerrogativa regia de la legislación y ejercicio de la justicia hace que la labor teórica de los oficiales de la Corona quede oscurecida por la figura del monarca que se coloca a la cabeza de la empresa. Estos problemas se encuentran perfectamente ejemplificados en las realizaciones del portugués Ruy Fernandes. A él se le debe parte de esa compilación legislativa comenzada bajo el reinado de don Duarte y conocida como las Ordenações Afonsinas, probablemente la organización de los libros II al V.

Como ya se ha apuntado, algunos de los obispos diplomáticos figuran entre los más egregios de su diócesis como benefactores y, en cierta manera, mecenas. La otra cara de la moneda es su constante absentismo, con toda probabibilidad debido a sus continuas colaboraciones en la política de

\footnotetext{
38"Berengarius Bardessinus, quo neminem ne illius ne huius temporis iurisconsultu in Hispania senes meminerunt maioris autoritatis fuisse..." Lorenzo VAlla, Historiarum Ferdinandi..., o. c., p. 99 y Crónica de don Juan II de Castilla, en Crónicas de los reyes de Castilla, t. II, Madrid, 1953, "BAAEE", p. 337.
} 
sus soberanos: Dalmao o Dalmacio de Mur comenzó su carrera como arcediano de la iglesia de Gerona en 1409. A partir de 1415 fue obispo de la misma diócesis, poniendo entonces gran interés en la continuación de la fábrica del templo. Tras ser erigido arzobispo de Tarragona en 1419, terminó su vida como titular de la sede zaragozana, entre 1431 y 1456. En esta última etapa, construyó a su costa el salón del palacio episcopal, aderezó los castillos y casas de la mitra y regaló a la Seo el coro, la fábrica del pedestal del altar mayor y muchos ornamentos litúrgicos ${ }^{39}$. Durante su embajada en París, compró la biblia equivocadamente llamada de Carlo Magno. En su testamento la donó a la catedral de Gerona, que entró en posesión de ella el 10 de octubre de $1456^{40}$.

Igualmente en la Corona de Aragón, Domingo Ram y, con menor éxito, García Aznar de Añón se distinguieron en la creación o reforma de centros universitarios. Sus medidas se enmarcan dentro de la política cultural de Alfonso el Magnánimo, que continúa la emprendida en la segunda mitad del siglo XIV y los inicios del XV por Pedro el Ceremonioso y Martín el Humano y se prolonga hasta el reinado de Juan II, en las décadas de 1470 y $1480^{41}$. En este contexto, las preocupaciones de los dos prelados se plasmaron en la universidad de Lérida, cuando ejercían la titularidad de su sede: don Domingo promulgó los estatutos para el colegio de Nuestra Señora de la Asunción, en torno a $1430^{42}$. A su sucesor se le atribuye el intento de reforma de la universidad en 1447 , que recogía los puntos principales de los privilegios de Martín I y las providencias del Magnánimo, con el fin de aplicarlas conjuntamente con las bulas recibidas de Eugenio $\mathrm{IV}^{43}$.

En Castilla, lo más frecuente fue la fundación de colegios en Salamanca por sus propios obispos, que, en cambio, no tienen un acusado

\footnotetext{
${ }^{39}$ Jaime VIllanueva, Viage literario a las iglesias de España, t. XIV, Madrid, 1850, p. 29 y Ángel CANELlaS LóPEZ, Historia de Zaragoza, t. I, Zaragoza, 1976, p. 413.

${ }^{40} \mathrm{~J}$. VILlanueva, Viage literario, o. c., p. 109.

${ }^{41}$ Para una visión de conjunto, véase $\mathrm{M}^{\mathrm{a}}$ Isabel FALCóN, ${ }^{\mathrm{a}}$ Luisa LEDESMA, Carmen ORCÁSTEGU y Esteban SARASA, Las universidades del reino de Aragón (Huesca y Zaragoza) y de Lérida en la Edad Media, Salvador ClaRAmUNT, Orígenes de las universidades catalanas medievales, en "Estudios sobre los orígenes de las universidades españolas", Universidad de Valladolid, 1988, pp. 69-85 y 85-97 y S. Claramunt, Las universidades en la Corona de Aragón durante la Edad Media, en Santiago AGUADÉ NIETO (coord.), Universidad, cultura y' sociedad en la Edad Media, Universidad de Alcalá de Henares, 1994, pp. 53-67.

${ }^{42}$ C. AJo, Historia de las universidades hispánicas, t. I, Madrid, 1957, p. 403.

${ }^{43}$ J. Lladonosa Pujol, Lérida medieval, t. II, Lérida, 1975, p. 28.
} 
peso político. Pero Diego de Badán o Mayorga, embajador a Aragón en 1424, titular de la sede de Cartagena y maestro en teología, volcó sus esfuerzos en su villa natal. Ese mismo año fundó un estudio en Mayorga de Campos, aunque todo parece indicar que no alcanzó una verdadera relevancia ${ }^{44}$.

Indudablemente, no existen unos vínculos directos entre la representación diplomática y el impulso a los centros universitarios, pero no deja de ser sintomático que éste fuera emprendido, entre otros, por algunos de los más decididos colaboradores de los soberanos tanto en política interior como en la exterior. Al fin y al cabo, los oficiales y miembros del Consejo Real que llevaron a cabo estas dos vertientes de la política surgieron de las filas de esta institución. Es más, en los momentos de máximo enfrentamiento político entre Castilla y Portugal se recurrió a profesores de la universidad de Salamanca y Lisboa para que, dentro y fuera de la diplomacia, proporcionaran argumentos en defensa de las reivindicaciones de los reinos respectivos. Baste señalar la actuación de miembros de la universidad de Lisboa en las décadas de 1380-1390, y la de los profesores de la de Salamanca Antón Sánchez de Salamanca y Rođrigo Maldonado de Talavera, en las de 13901400 y $1470-1490$, respectivamente.

\section{ACTIVIDADES DIPLOMÁTICAS Y REALIZACIONES CULTURALES}

Al contrario de lo que ocurrió en buen número de embajadas a Roma o a las asambleas conciliares, las que tuvieron lugar entre los tres principales reinos de la península ibérica no tuvieron apenas incidencia en la adquisición de libros o en el incremento de la producción intelectual y artística. Pero esto no significa que los contactos carecieran de importancia. Antes bien, los vínculos clientelares, la ayuda militar en los conflictos bélicos, los exilios nobiliarios o las alianzas matrimoniales, que jalonan toda la centuria, contribuyeron a que las relaciones peninsulares cobraran tal intensidad que no precisaran, en general, de la presencia diplomática. Por citar solamente algunos datos en apoyo de este aserto, la vinculación de Iñigo López de Mendoza a los Trastamara aragoneses se establece durante la adolescencia

\footnotetext{
HVicente Beltrán de Heredia. Bulario de la universidad de Salamanca (1219-1549). t. II, Salamanca, 1966, pp. 249-250
} 
del futuro marqués. El infante-regente don Pedro de Portugal figura entre los poetas de algunos cancioneros castellanos y escribió en esta lengua " De contempto del mundo ", en donde alude a don Álvaro de Luna, además de componer unos loores a Juan de Mena en su propio idioma ${ }^{45}$. En 1445, mandó a guerrear en Olmedo a su hijo homónimo, quien trabó allí conocimiento con el marqués de Santillana y, a su vuelta a Portugal, le solicitó un ejemplar de sus Canciones e dezires ${ }^{46}$. Las grandes recopilaciones poéticas de toda la centuria y los inicios del siglo XVI muestran la abundancia de los contactos entre literatos de los tres países o el envío de sus rimas a señores y damas, oriundos de otros territorios peninsulares o residentes eventualmente en ellos.

Por otra parte, la relativa cercanía entre las respectivas cortes explica que las estancias diplomáticas fueran, en general breves, y poco aptas para un contacto profundo.

No es de extrañar que la única excepción relevante concierna a las relaciones con Portugal durante la década de 1420 y comienzos de la siguiente, época en la que acuden figuras notables y en estancias más duraderas o repetidas que lo habitual. Por otra parte, la cultura cortesana recibe un nuevo impulso por la actuación de don Duarte desde su etapa de heredero y colaborador de su padre en las tareas de gobierno. Lamentablemente, la biblioteca regia se ha perdido, por lo que es imposible saber si algunos de sus libros en "castelão" o "aragoes" le fueron proporcionados por los agentes de estos países ${ }^{47}$. Con todo, existe constancia de la influencia en sus empresas intelectuales de García Aznar de Añón y, sobre todo, de Alfonso García de Santa María.

El primero -enviado plenipotenciario de Aragón en 1432- conoció por el rey el trato y conversaciones que éste y sus hermanos tenían con su padre, don João I, y le indujo a redactar sus pensamientos sobre este tema, mostrándole el interés de los infantes de Aragón en tenerlos por escrito, lo

\footnotetext{
${ }^{45}$ GaRCIA DE RESENDE, Cancioneiro Geral, o. c., t. I, n"is 256-257, pp. 247-263.

${ }^{46}$ Oliveira Martins, Os filhos de don João I, o. c., p. 241 y nota 497, p. 338.

${ }^{47}$ La relación de volúmenes está contenida en el Livro dos conselhos de el-rei $D$. Duarte (livro da cartuxa), ed. de A.H. de Oliveira MARQues y João Alves Dias, Lisboa, 1982, pp. 206-208.
} 
que dio origen a una carta de don Duarte, el 25 de enero de 1435, que más tarde fue incorporada al Livro dos conselhos y al Leal conselheiro ${ }^{48}$.

Mucho más decisiva fue la intervención de Santa María en la corte lisboeta. En el orden literario, durante su estancia allí terminó la traducción, comenzada por el canciller Pero López de Ayala, del De casibus virorum de Bocaccio, a instancias del secretario de su propia embajada, el bachiller en decretos Juan Alfonso de Zamora. Esta versión, conocida como la Caída de príncipes tuvo una importancia clave en el horizonte cultural de la aristocracia castellana, ya que se convirtió en una de las obras de mayor presencia en sus bibliotecas a partir de la década de 1440. También dejó sus huellas en la cultura portuguesa, a juzgar por las abundantes referencias en las crónicas de la época.

A instancias de don Duarte compuso en 1422 el Memorial de virtudes, un resumen comentado de las Éticas de Aristóteles que incorpora alusiones a la historia del medievo hispánico ${ }^{49}$. Seguidamente, comenzó a traducir la Retórica de Cicerón. Sin embargo, según expone en la introducción de este último tratado el entonces deán de Santiago, únicamente había realizado una pequeña parte cuando tuvo que regresar a Castilla. Entonces se comprometió a terminar la tarea y, quizás por ello, dejó una pequeña parte en Portugal como garantía de que cumpliría el acuerdo ${ }^{50}$.

La estancia en Portugal de don Alfonso dio también sus frutos en un escrito considerado de segundo orden dentro de su producción, pero que es un perfecto ejemplo del uso de argumentos jurídicos e históricos para reivindicar la legitimidad de unas posesiones por un reino: sus alegaciones en defensa de los derechos de Castilla a las Canarias ${ }^{51}$. Como su mismo

\footnotetext{
${ }^{48}$ Livro dos conselhos..., o. c., pp. 100-11 y D. DUARTE, Leal conselheiro, ed. de João MORAIS BARBOSA, Lisboa, 1982, pp. 416-431.

49 "E no Memorial das Virtudes que das Éticas de Aristóteles me ordenou o adião de Santiago..." Leal conselheiro, o. c., p. 248.

${ }^{50}$ Joaquim BARRADAS DE CARVALHo, Estudos sobre a cultura portuguesa do século XV, Coimbra, 1949 , p. 35 y ss.

${ }^{51}$ Una copia del texto original latino, del 27 de agosto de 1437, se encuentra dentro del conjunto de documentos relacionado en el concilio de Basilea, contenido en el AGS. Estado-K, leg. 1711. Corresponde a los folios 131-146 v. Los argumentos fueron traducidos al castellano y extractados por Alfonso GARCía GAllo en Las bulas de Alejandro VI y el ordenamiento jurídico de la expansión portuguesa y castellana en África e Indias, "Anuario de Historia del Derecho Español, (1958), pp. 752-765. Para el papel de este informe en el marco de la pugna entre los dos reinos por la posesión de Ceuta, Canarias y Guinea, véase Paz RomERo PORTILLA, La rivalidad luso-castellana desde 1415 a 1479 por la legitimidad sobre las tierras conquistadas, en "La península en la era de los descubrimientos", o. c., t. II, pp. 1745-1752.
} 
nombre indica, se inscribe en un tipo de escrito común en procedimientos procesales ligados a un recurso, y que consiste en exponer argumentos y fundamentos jurídicos en respuesta a otros. En el redactado por García de Santa María queda patente que su saber y experiencia en el país vecino revirtió en contra de éste. En efecto, durante su participación en el concilio de Basilea representando a Juan II de Castilla responde a un llamamiento regio, dirigido a sus embajadores que hubieran hablado con los reyes portugueses Juan y Eduardo sobre la conquista de las Canarias y estuvieran informados de los posibles derechos de éstos ${ }^{52}$. Los destinatarios que cubrieran tales requisitos deberían remitir un informe al negociador en la curia romana, Luis Álvarez de Paz, que le proporcionara razonamientos con los que conseguir del papa la revocación de la bula que había otorgado a don Duarte, concediéndole el derecho sobre las islas. Las réplicas de don Alfonso a las tesis portuguesas revelan un profundo conocimiento de ellas, tanto en su transfondo teórico como en la forma de presentarlas ante el pontífice, y también del conjunto de gestiones políticas utilizadas para ponerlas en práctica y no hay duda de que el informe consiguió sus objetivos, pues la nueva bula, del 31 de julio de 1436, proclamaba la legitimidad de los castellanos. Más allá de sus pormenores, este episodio nos indica que la labor de un buen diplomático no se concebía únicamente como la resolución de un asunto concreto, sino que debía estar atento a cuanto pudiera afectar, directa o indirectamente, a la actuación política y a la persona de su monarca, mantener informado a éste y oponerse a lo que pudiera ir en su detrimento. Y, en función de todo ello, era valorado como un especialista en los problemas internacionales en los que había intervenido.

\section{EL RECONOCIMIENTO DE LAS CUALIDADES PROPIAS DEL EMBAJADOR}

En la segunda mitad de la centuria, se registran con cierta frecuencia adjetivos o expresiones calificadoras de estos personajes. Suponen una importante novedad con respecto a las elogios del período anterior, puesto que no aparecen en semblanzas biográficas o en menciones de actividades

\footnotetext{
$52 " .$. fuerant locuti cum domino Johanne tunc rege portugaliae ac domino Eduardo rege moderno circa conquestam insularum canarie et erant informati de iure suo... " AGS. Estado-K, leg. 1171 , fol. $131 \mathrm{r}$.
} 
señaladas en el campo de la política interior, sino que se introducen en las noticias cronísticas sobre el envío de la embajada. Por tanto, pueden considerarse, a la vez, un epíteto para el individuo y para el oficio de representante en el exterior.

Los textos más claros, en este sentido, son las crónicas portuguesas de Gomes Eanes de Zurara y Rui de Pina, en donde se define a algunos embajadores como personas de gran autoridad o prudentes. Por lo general, son denominados así aquellos que actuaron en conciertos capitales dentro de las relaciones exteriores y, en consecuencia, se incluyen los negociadores con Castilla en las paces de 1411 y 1479 y el tratado de Tordesillas ${ }^{53}$, aunque también se extiendan estos calificativos a algunos delegados castellanos en otros contactos. En las crónicas de este último país aún adquieren un carácter más solemne, puesto que las alusiones a la autoridad o a la prudencia se adjuntan a propósito de los contactos con Roma, lo que indica que existía una lógica correspondencia entre la importancia del poder con el que se efectuaban los contactos, el asunto a tratar y la valía del delegado ${ }^{54}$.

El ser considerado una autoridad no expresa únicamente, en esta segunda mitad de la centuria, el destacar como perito en una materia determinada. Tiene un sentido más amplio. Significa el poseer credibilidad, prestigio, tanto por las palabras utilizadas y las obras realizadas a lo largo de toda la trayectoria vital como por el ingenio y los conocimientos que denotan. El individuo que goza de autoridad se convierte en un punto de

\footnotetext{
${ }^{53}$ "Os quais embaxadores eram João Gomes de Silva, alferes de-el Rei e rico homem e do seu conselho, e Martin Dossem, governador da casa do Infante Duarte, e o doutor Beliago, adaião da Sé da Coimbra, todos trés e cada um em seu estado eram notaveis pessoas e de grande autoridade". GOMES EANES DE ZURARA, Crónica da tomada de Ceuta, ed. de Reis Brasil, Sintra, 1992, p. 49. "El Rey tornou a enviar por seus Embaixadores e procuradores ... Ruy de Sousa, e ho licenciado Aires d'Almadaã, e Estevam Vaaz por Escripvam, pessoas no Reyno de bõo saber, grande fiança, e muita autoridade..." Ruy de PINA, Chronica d'El Rey D. Joaõ II Cronicas de Rui de Pina, o. c., p. 1018. De João Fernandes de Silveira se resalta su prudencia, pero no con ocasión de sus repetidos tratos con Castilla, como ocurre con los anteriores, sino a propósito de sus gestiones previas al matrimonio de la infanta doña Leonor con el emperador: "Foy logo pera ysso ordenado por Embaxador, o Doutor Joam Fernandez da Silveira, homem Fydalgo prudente e gram letrado". Ruy de PINA, Chronica do senhor rey D. Affonso V, Cronicas de Rui de Pina, o. c., p. 759.

${ }^{54} \mathrm{~A}$ Alonso de Palencia y a sus acompañantes a Roma, para tratar del gobierno de Enrique IV, se les llama "grandes letrados y de grande autoridad". Don Iñigo López, elegido para otra misión en Roma, es descrito como "caballero prudente y gracioso, segund que para tal embaxada convenia". Diego de VALERA, Memorial de diversas hazañas y Diego ENRÍQUEZ DEL CASTILlo, Crónica de don Enrique IV, Crónicas de los reyes de Castilla, t. III, Madrid, 1953, "BAAEE", pp. 30 y 112
} 
referencia para sus contemporáneos, de manera similar a la de los grandes autores clásicos y cristianos. Participa de la sabiduría, lo que queda patente, en cuanto a estos embajadores, en una época algo posterior a ésta, entre 1530 y 1533, cuando el cronista luso Garcia de Resende define a sus compatriotas que negociaron en Tordesillas como personas "de muyto bom saber, grande confiança, e muyta autoridade" 55 .

En cuanto a la prudencia, constituye la virtud esencial del gobernante, lo que explica la atención que le dedican los tratadistas políticos e, incluso, los poetas cortesanos ${ }^{56}$. Para don Duarte engloba, entre otros aspectos, la facultad de prever los acontecimientos y actuar conforme e ello, gobernar de acuerdo con unas reglas de conducta, discernir lo útil y beneficioso y tomar las opciones correctas. Implica el ingenio, el entendimiento, la agudeza, el juicio claro, la discreción, la mesura en palabras y acciones. Por tanto, puede incluir la reputación de autoridad, tanto en el sentido moral como en el intelectual.

El valor que se le otorga como atributo supremo del buen dirigente, al lado de la justicia, denota la gran influencia en este período de la filosofía y la retórica greco-romana. Al mismo tiempo, conecta con la equiparación entre realeza, sabiduría, justicia, piedad y valores cristianos que ya aparecía en Las siete partidas, y que no solo operaba entonces en Castilla sino en todo el conjunto de los reinos hispánicos.

Unida a la fama de autoridad, la prudencia se integra en la semblanza del infante-regente don Pedro de Portugal y, de forma más velada, en la de don João $\mathrm{II}^{57}$. Hay que tener en cuenta que, a nivel

\footnotetext{
${ }^{55}$ GARCIA DE RESENDE. Chronica dos valerosos, e insignes feitos del rey dom Joam II, en Crónica de D. João II e Miscelânea, Lisboa, 1973, p. 243.

${ }^{56}$ Don Duarte le dedica ocho capítulos de su Leal conselheiro y trata de ella, unida al resto de las virtudes cardinales y teologales en otros cuatro (pp. 248-270, 277-297, 303-308 y 312314). Dentro de los cancioneros, baste señalar que sus características están explicadas en la "Flor de virtudes" del Cancionero de Juan Fernández de Ixar. contraponiendo esta cualidad a la locura como vicio contrario (ed. de José María AZACETA, Madrid, 1956, t. II, pp. 714-716) y Gómez MANRIQUe le da la palabra, junto con las otras virtudes, en su " Regimiento de príncipes", dirigido a los príncipes de Castilla y Aragón y futuros Reyes Católicos (GómEZ MANRIQUe, Cancionero, o. c., t. II, pp. 179-181).

${ }^{57} \mathrm{De}$ don Pedro dice Ruy de Pina que "sus roupas e trajos e maneyra de viver, foram sempre de homem honesto, prudente, e grande autorydade ..." En cambio, la prudencia del "Principe Perfeito" no está mencionada claramente por este autor, sino que la presenta a través de sus rasgos básicos: "Foy Principe de maravilloso engenho, e subida agudeza... e teve ho juizo craro, e profundo: e porem suas Sentenças, e fallas que inventava, e dezia, tinham sempre na invençam mais de verdade, agudeza, e autoridade, que de doçura..." Chronica do senhor rey D. Affonso V y Chronica d'elrey D. Joaõ II, o. c., pp. 753 y 1029.
} 
general, se produce en este período un refuerzo de la exaltación ideológica del poder. En el reino luso, los Avís insisten para ello en una imagen de la dinastía, basada entre otros factores, en la santidad y, además impulsan a la historia nacional y la recepción de los autores clásicos. Dentro del ámbito cultural, conecta con un proteccionismo de los monarcas y sus familiares, que tiene precisamente al infante don Pedro entre sus principales protagonistas $^{58}$.

El carácter de prerrogativas regias de la prudencia y la autoridad y su aplicación a los embajadores indica un paso más en el reconocimiento de que éstos constituyen una emanación del poder emisor y de que, en conjunto, las relaciones internacionales son una pieza clave para la prosperidad del reino-Estado.

Conviene recordar que el siglo XV supone la cristalización plena de las instituciones diplomáticas y el tránsito hacia una práctica formalizada. Y, en consecuencia, el oficio de sus agentes comienza a ser el objetivo de ciertos tratados teóricos. Así, el cronista castellano Alfonso de Palencia, que había participado en tratos con Roma y Aragón, escribe el De uera sufficientia ducum atque legatorum ${ }^{59}$. Lamentablemente, esta obra se ha perdido, por lo cual sólo se pueden conocer algunos de los puntos de vista defendidos por el autor a través de la descripción de algunos representantes, introducida en los primeros libros de su Gesta hispaniensia.

Algunas de las breves estampas dedicadas a ellos son claramente peyorativas. En principio, obedecen a una voluntad individualizadora, propia del final del medievo y el primer Renacimiento, y a la finalidad política de denigrar a Enrique IV a través de sus colaboradores ${ }^{60}$. Al mismo tiempo, se mueve entre la crítica moralista y la aceptación del cinismo de los nuevos tiempos, en los que el disimulo es exaltado como si fuera la agudeza, que es expresión de la prudencia. Esta visión contrapuesta se encuentra perfecta-

\footnotetext{
${ }^{58}$ I. BECEIRO PITA, Cultura, ideología y mecanismos de gobierno en la dinastía lusa de los Avís, "Signo. Revista de historia de la cultura escrita", 5 (Alcalá de Henares, 1998), pp. 9-34.

${ }^{59}$ Brian TATE y Jeremy LAWRANCE, Introducción a Alfonso de PALENCIA, Gesta hispaniensia ex annalibvs svorvm dierum collecta, t. I, libri I-V, Madrid, 1998, pp. XXXV-LV.

${ }^{60} \mathrm{~A}$ Álvar García de Ciudad Real, que inicia los tratos para el segundo matrimonio de Enrique IV, lo define como" necio, ignorante por naturaleza, de bajo origen y bajas inclinaciones" y agrega que "Enrique, como era su costumbre, apenas hubo subido al trono, lo quiso nombrar su secretario, como si aquel cargo y su ejercicio correspondiesen de derecho a algún hombre completamente inhábil, oscuro y depravado". Alfonso de PALENCIA, Gesta hispaniensia, p. 104.
} 
mente reflejada en la "pintura" de Pedro Vaca, enviado por Alfonso el Magnánimo a Castilla en 1455: " hombre hábil para estas embajadas, porque estaba estrechamente emparentado con el marqués y su profundo conocimiento de los asuntos de España le habían enseñado a devolver golpe por golpe, conducta necesaria para los mensajeros, heraldos, terceros y embajadores de aquel tiempo cuando el simular, disimular, insimular, mentir y hablar con osadía pasaba generalmente por agudeza suma o pericia consumada. De todo Pedro Vaca fingía hábilmente no haberse apercibido, o, si confesaba saberlo sacaba un clavo con otro clavo. Pequeño de cuerpo pero bastante resuelto en tales asuntos, empleaba la porfía o la mansedumbre según la naturaleza del negocio, aparentando encolerizarse a veces y desistiendo de repente de su propósito. Esas cualidades lo recomendaban como embajador al rey sagaz"61.

En definitiva, estos pasajes responden a dos concepciones que coexisten en la segunda mitad del siglo XV: por una parte, el embajador es un trasunto de las cualidades del poder y su capacidad o ineptitud se corresponde con la del gobernante responsable de su nombramiento; por otra parte, su cargo se concibe como un oficio de la administración y su titular debe desarrollar su tarea con eficacia, haciendo abstracción de los medios empleados para ello. Pero, de cualquier forma, encarnar adecuadamente estos principios requería dosis considerables de pericia, discreción, conocimientos, educación y cultura.

\section{RÉSUMÉ}

Cet article analyse les causes de l'importance croissante acquise par la culture dans les relations entre les principaux royaumes ibériques au cours du $\mathrm{XV}^{\mathbf{c}}$ siècle. À cette époque de renforcement des institutions des diverses monarchies, il met en évidence à la fois le caractère de l'ambassadeur comme émanation de l'autorité royale et comme représentant de la cour de son pays, et par ailleurs, l'exigence que lui est faite de posséder des connaissances techniques, essentiellement juridiques, afin de pouvoir exercer au mieux ses devoirs de diplomate.

\footnotetext{
${ }^{61}$ Gesta hispaniensia, p. 142.
} 


\section{SUMMARY}

This article analyzes the reasons for the increasing importance of culture in the relations among the principal Iberian kingdoms throughout the 15 th century. During this period, when the institutions of the different monarchies grew in strength, ambassadors were considered emanations of royal authority and representatives of the court of their country. While at the same time they were expected to have technical, and above all juridical knowledge, in order to adequately carry out their diplomatic tasks. 